\title{
Review of Land Cover Classification Based on Remote Sensing Data
}

\author{
Yi Wang \\ Institute of Meteorology \& oceanography \\ PLA University of Science \& Technology \\ Nanjing, 211101,China \\ e-mail: wangyi_rsc@126.com \\ Jie Xiang \\ Institute of Meteorology \& oceanography \\ PLA University of Science \& Technology \\ Nanjing, 211101,China
}

\author{
Ming-Yuan He \\ Institute of Meteorology \& oceanography \\ PLA University of Science \& Technology \\ Nanjing, 211101,China \\ Ze-Ming Zhou \\ Institute of Meteorology \& oceanography \\ PLA University of Science \& Technology \\ Nanjing, 211101,China
}

\begin{abstract}
Land use and land cover change is one of the focuses in the study of global change in recent year. Land cover characteristics, at the global and regional scale, are very important for evaluating global environment status and simulating global environment scenario in the future. In order to provide some useful reference for this kind of study in China, the paper introduces the most recent progresses of international researches on land cover classification from four aspects including remote sensing data, classification method, land cover classification system and outcome comparison. The author believes making a classification system not only reflects the Chinese condition but also being compatible with other international systems, building a public and updating land use/cover database, are the most important things to be solved.
\end{abstract}

Keywords-Land cover classification; Land use; remote sensing data.

\section{INTRODUCTION}

Land cover is to point to the earth's land surface cover of various biological or physical types, including vegetation (natural or artificial) on the surface of the earth, the human right to use construction land, buildings, roads), lakes, glaciers, bare rock and desert, etc., mainly describe the nature of the surface of the earth[1]. With global change science research and development of earth observation technology, since the $1990 \mathrm{~s}$, the world has carried on the deepening to the concept of land cover, land cover and its characteristics of a new understanding of the meaning of land cover is no longer a single land and vegetation types, but the land type and has a series of complex nature and the humanities characteristics, including the land type and vegetation canopy density, dynamic characteristics of the vegetation growing season, growing season cumulative biomass, surface coverage of biophysical characteristics and the humanities to land use and the humanities building, etc. In addition, the synthesis but also is closely related to land cover types of ecological environmental elements, such as vegetation's ecological region, topography, climate conditions and soil physical and chemical properties, etc.
This with multi-dimensional information on land cover types as the core concept of complex can not only in theory is more accurate and complete to describe characteristics of land cover and land use, and also has important significance in practical application[2]. Since 1990, the international geosphere and biosphere program (IGBP) and the "humanistic factors of global environmental change plan" (IHDP) actively planning global comprehensive study plan, drawn up in 1995 and published "the science of land use/land cover change research plan, will be one of it as a core project of global change research[3].

Remote sensing for macro speeds up the distribution of the dynamic understanding of the land cover possible. At present, for a global, intercontinental and regional different scales of land cover classification and land use/land cover change research, AVHRR and MODIS, TM, Vegetation data has become an important source of land cover and change detection research, plays an indispensable role in environmental monitoring. Below from remote sensing data, classification methods, classification system and the result comparison is presented in four aspects.

\section{LAND COVER ClassificAtion UsED IN THE DATA}

Using remote sensing data to carry on the dynamic monitoring of land use/land cover, study of large area generally with low spatial resolution data (AVHRR and MODIS data), and local land use investigation general MSS using high spatial resolution image and TM image, the SPOT image, or the combination between them, also some people choose study on land cover classification of SAR radar image. Choose remote sensing data should be considered the size of the study area, the research purpose, significance and so on, in order to achieve required accuracy, at the same time, avoid causing unnecessary waste.

\section{A. From NOAA NDVI to MODIS EVI}

The use of remote sensing data for land cover classification research, mainly including the single phase image classification, image classification, long long phase phase images and three aspects of secondary data 
classification. Early classification studies generally USES single phase images or long phase, are often using remote sensing data and secondary data combining the way of land cover classification.

The earliest application for phase AVHRR normalized difference vegetation index (NDVI) intercontinental scale land cover classification is Tucker [4] and Townshend [5], they respectively studied the Africa and South America. Cihlar [6], such as using NOAA data for land cover classification in Canada, the NDVI, channel a $(0.58 \sim 0.68$ (including $\mathrm{m}$ ) albedo $\mathrm{C} 1$, channel 2 (0.725 1.0 (including m) albedo C2 and channel $4 \mathrm{~m}$ (10.3 11.3 (including) compares the $\mathrm{C} 4$ bright temperature, the results show that the NDVI is the best of the single feature classification performance, followed by C2, C1, C4. Also prove that NDVI used together with other features, can get a higher classification accuracy.

On a global scale, IGBP in 1997 completed the spatial resolution of $1 \mathrm{~km}$, time resolution vegetation index for 10 days. The data with the data published in succession before, constitute a relatively complete data sequence. In addition to the vegetation index information, also including the NOAA AVHRR five band number and Angle of the sun, sensors, relative azimuth Angle, chosen as yuan date, etc. Use $1 \mathrm{~km}$ spatial resolution remote sensing data to prepare the land cover map of global or regional scale, the advantage of data from high resolution of time, especially the synthesis of NDVI data can well reflect the surface vegetation phenological characteristics and changes.

In 1999 and 2002, the United States launched Terra and Aqua satellites, with moderate resolution imaging spectroradiometer (MODIS), so far has been from MODIS instrument of the tenth year of continuous global land data. MODIS land cover/land use change research team is now testing a change of the every 3 months $1 \mathrm{~km}$ resolution of global land cover map, updated once every 16 days of 0.5 $\mathrm{km}$ resolution vegetation index figure, updated once every eight days $1 \mathrm{~km}$ resolution of leaf area index figure, and updated daily $1 \mathrm{~km}$ resolution in the total primary productivity and net primary production is trying to [7]. MODIS data has become the latest data in the study of land cover, in addition to raising the ground resolution, MODIS enhanced vegetation index (EVI) in than AVHRR vegetation index design and synthesis algorithm, etc - NDVI has a bigger improvement. Huete etc. [8], zheng-xing wang etc. [9] research shows that the MODIS EVI - compared with AVHRR - NDVI, tend to be low part (the same target, MODIS EVI than AVHRR NDVI value low), it is not easy to saturation, suitable for the monitoring of high biomass groups. Strahler, etc. [7], Liu Yonghong [10, 11] are successively carried out using MODIS data at different scales of land cover classification.

\section{B. Secondary Data}

Secondary data can improve land cover classification accuracy to a certain extent, the commonly used secondary data including elevation, latitude and longitude, the surface temperature, the average annual accumulated temperature, annual average precipitation, the greatest possible evaporation, texture, and so on. MODIS land cover/land use change research team in addition to using enhanced vegetation index in classification, also used the channel $1 \sim 7$ albedo data, the surface temperature data, land and water, ice and snow marking data, terrain elevation data and texture information of optical channel [7]. Cihlar [6], such as research has shown that the introduction of secondary data to identify water bodies, can avoid the classification of water area is narrow; The authors also emphasize the temperature data in a wide range of research areas (latitude span large area) can play a greater role. Palace [12] using MODIS NDVI data - such as climbing to land cover classification research of northeastern China, after the introduction of the surface temperature data, a year a ripe crops with high coverage grassland, deciduous coniferous forest and deciduous broad-leaved mixed phenomenon in a certain extent solved. Liu Yonghong [10] in the classification characteristics such as joined the longitude and latitude information, the author thinks that for large scale of regional land cover classification, the characteristics can play a role, for example, in China's regional one year practice of farmland is distributed in the north of the Yellow River, and the distribution of three ripe crops a year in low latitude area; If a province or a smaller scale classification, latitude and longitude information may not work. Ai-xia liu [13], such as the annual accumulated temperature and average annual precipitation is introduced into the classification, NieJuan [14] will Thornthwaite index system of evapotranspiration (possibly evapotranspiration, moist index, precipitation and elevation information) as indicators of climate, vegetation classification, have achieved good results.

\section{LAND COVER Classification Used IN THE METHOD}

\section{A. Based on the Theory of Statistical Classification Method}

Statistical methods are widely used in the early, in remote sensing image classification has a lot of mature algorithms. According to the classification before access to the training sample category a priori information can be divided into two categories: supervised classification and unsupervised classification.

Supervised classification is to point to in the condition of known samples category, embarks from the training set that each category of statistical information, and then based on these statistics combined with certain criterion to juggling all pixels that have similar characteristics and meet certain criterion for the pixel incorporated into the category. The commonly used supervised classification method and maximum likelihood classification method, decision tree classification, Parzen window method, $\mathrm{K}$ - nearest neighbor method, etc.

Maximum likelihood classification is one of the most widely used type of classifier, it has a strict statistical theory foundation, Tucker, etc. [4], Borak etc. [15] in land cover classification by using this method. Normally the classification results of maximum likelihood classification as a measure to evaluate the stand or fall of other classification methods, compared with methods such as decision tree, 
neural network, the classification of the maximum likelihood classification accuracy is low. Due to the flexible, intuitive, and decision tree algorithm has better computation efficiency is high, in the land cover classification favored by more and more people, especially in the classification of continental and global scale. DeFries [2], such as using $8 \mathrm{~km}$ spatial resolution AVHRR data combined with decision tree classification method for land cover classification, achieved satisfactory results, Friedl, etc. [16] the results showed that the decision tree method in the large-scale land cover classification show good robustness. Hansen, etc. [17], [18] such as Swain think for land cover classification using decision tree method can both classification accuracy and classification efficiency. Parzen window method is a kind of has a solid theoretical foundation and excellent performance of nonparametric density estimation methods, Liu Yonghong [10] in using MODIS data in north China for land cover classification in Parzen window method and decision tree, neural networks, such as maximum likelihood classification were compared, Parzen window classifier performance is optimal.

Classification method has been discussed above are on the basis of the known categories TAB sample set. In many practical applications due to lack of knowledge formation model class, often only get no category label sample set, which is called non-supervised classification. The method is based on the statistical characteristics of image, assuming the same features with similar spectral reflection of value, the same feature in the feature space there is a point of "point group". The commonly used unsupervised classification method is for clustering method. Han [19], such as using the $1 \mathrm{~km}$ resolution SPOT/Vegetation data using k-means clustering method to the French region of land cover classification, clustering method is pointed out that the key is to determine the number of initial category and the category of calibration. Ai-xia liu [20], such as fuzzy k-means clustering method was used to study the northwest of Beijing land cover classification, the results show that the method can achieve a larger range of land cover classification, and can achieve higher classification accuracy. YuFeng etc. [21] based on NDVI - TS feature space using the ISODATA clustering method to classify China's regional land cover, good results have been achieved.

\section{B. Based on the Classification Method of Artificial Intelligence}

1. Artificial neural network classification

Using artificial neural network method to classify remote sensing data began in $90 \mathrm{~s}$ of the 20th century, the research content including land cover, botany class identification and so on. Most of the research adopts the method of supervised classification, there is also a part of work unsupervised classification methods, such as land cover classification using self-organization neural network. In almost all the work, the neural network classifier is better than the traditional classification method, the result many studies have shown that the overall classification accuracy can improve $10-20 \%$. With neural network successfully applied in the field of remote sensing to the rising number of examples, people more clearly aware of the neural network classifier is better than the traditional method of the reason is that: (1) neural network classifier does not need to estimate for each category of data distribution in advance; (2) to deal with nonlinear and discontinuous distribution of data; (3) neural network classifier is easy to absorb the classification characteristics such as texture, elevation and direction.

Most of the application of neural network in the field of remote sensing using the error back propagation multi-layer forward network, the BP neural network, the network using gradient descent method to meet local or global optimal. However this kind of network learning methods exist shortcomings: (1) the network is very sensitive to initial value; (2) the existed study question. Using the adaptive resonance theory (ART) can overcome this problem, as the learning algorithm of adaptive neural network performance is very stable $(22,23)$. The MODIS land cover classification in the products adopt the Fuzzy ARTMAP method, this method is a set of Fuzzy logic and adaptive resonance theory in the integration of supervised classification method. Gopal et al. [24] using the spatial resolution of the period of one year for $1 \mathrm{~km}$ on synthetic AVHRR NDVI data - land cover was studied for the west African region, classification method using Fuzzy ARTMAP neural network, each category of classification accuracy between 66-98\%, the average accuracy is $83 \%, 61 \%$ of the superior to BP neural network. Fischer [25] using Landsat TM data such as studied in northern Austria Vienna city, compares the multi-layer perceptron network, radial basis function (RBF) network and Fuzzy ARTMAP neural network classification performance, the results show that from the classification accuracy and the network convergence time of the Fuzzy ARTMAP neural network is better than that of the multi-layer perceptron network.

2. Support vector machine (SVM) classification

In the $1990 \mathrm{~s}$, represented by mathematicians Vapnik school after years of research and development of a set of statistical learning theory and based on it the Support Vector machine (SVM) algorithm, Support Vector those, SVMs) [26]. The new algorithm can deal with nonlinear data, and can effectively restrict the fitting, is considered to be current for small sample classification and regression problems such as the best theory, application in aspects such as word recognition, speech recognition has been fruitful [27].

The effect of the support vector machine (SVM) classification has been proved that with the best classification method (such as neural network and decision tree classifier), in the classification of remote sensing data also has superior performance. Huang, etc. [28] in land use/land cover classification experiment compared the support vector machine (SVM), neural network, decision tree and maximum likelihood classification method of accuracy, robustness and speed, the results show that the support vector machine (SVM) classification accuracy is generally higher than the other three kinds of classification methods; Its robustness is far better than the other three; But its speed performance in general, by the size of training data, the parameters of the kernel function is set up and the influence of class separability. Chang [29] the support vector machine 
(SVM) method is adopted to MODIS data for land cover classification research, with the BP neural network and support vector machine (SVM) and maximum likelihood classification in different training sample under comparison, the results show that when the training sample, high dimension data, SVMs can effectively weaken the Hughes phenomenon is 1 , and classification accuracy is better than traditional method; On the learning speed, SVMs are superior to the BP neural network, but lower than the maximum likelihood classification. Wen-jie fu, etc. [30] will support vector machine (SVM) method is used for putian city land use classification, compared with maximum likelihood method, the classification of the SVMs total precision improved by $7.9 \%$, to $89.5 \%$.

\section{Classification Method Based on GIS}

Remote sensing image classification method based on knowledge, can the original GIS data and a new remote sensing image data organically unifies in together, make full use of various land use type change original transcendental knowledge, the knowledge used in remote sensing image classification. Some can't determine the classification levels of data can get better classification, and the result of classification is relatively more conform to the actual situation of the land use. Paul [31] studied under the GIS support, such as a superposition of matrix analysis, the result of the SPOT data classification in order to make classification image together with partition information of land use, accuracy increased to 78\%. Cumt-ger etc. [32] proposed a land use classification method based on knowledge, the remote sensing images and GIS data organically, with that of the conventional maximum likelihood classification results comparison shows that the classification method based on GIS is more precise, for dynamic monitoring of land resources utilization and environmental change provides a powerful tool. DiKai Chang [33], such as using data mining technology to discover knowledge from GIS database and remote sensing images, is used to improve the classification of remote sensing images, and the inductive learning combined with traditional image classification method used in Beijing area of land use classification, the results show that the inductive learning can better solve with different spectrum, with the spectrum of foreign bodies, significantly improve the classification accuracy, and can according to find further detailed classification of knowledge, expands the ability of image classification.

\section{About the LAND COVER Classification System}

To establish a standard classification system, and defined the category of the classification system of scale and the limitation of data source, is an important part of the study of the current land cover, makes sense for studying global change. Here are several main classification systems at home and abroad.

(1) the United States geological survey (USGS) land cover classification system. Anderson, supported by NASA, put forward a set of land cover classification system, divided into two levels, the first level includes six land cover types, the second including 18 classes, the system many categories of borrowing for land use categories [1]. Of Anderson, USGS in 1976 put forward the classification system is verified and evaluated, developed a kind of suitable for remote sensing classification system. The system based on satellite altitude or drawing scale is divided into four classes, the first and second world or continental scale research, the third, 4 class provides more detailed land cover information, apply to regional research. Based on TM Data to establish in the $1990 \mathrm{~s}$ the United States Land Cover Data NLCD (National Land Cover Data) is from the USGS Land Cover classification system developed [34].

(2) IGBP and UMD classification system. In the $1990 \mathrm{~s}$ the international geosphere biosphere program (IGBP) and the university of Maryland (UMD) for global area has been established based on AVHRR data of 17 categories of IGBP classification system [35] [36] and 14 kinds of UMD classification system. The classification system of UMD most agree with IGBP, not including IGBP classification system of permanent wetlands, crop/natural vegetation mosaics, ice/snow three land cover types. United States geological survey in order to establish the global land cover data sets of IGBP Strahler (DISCover) and Boston university and others [7] making global land cover classification of MODIS products (MOD12) adopt IGBP classification systems; The university of Maryland, global land cover data sets using the UMD classification system.

(3) the FAO and UNEP classification system, LCCS. In 1996, the United Nations food and agriculture organization (FAO) and the United Nations environment program (UNEP) trying to build a standard and comprehensive Classification System LCCS (Land Cover Classification System). This system is suitable for different users, each user using only part of the classification system, and according to the needs of research on this basis. The FAO classification system is mainly divided into two stages: one is the dichotomy phase (Dichotomous), consists of a series of independent diagnosis attribute to define the eight main land cover types; The second Phase is Modular Hierarchical classification stage (Modular - Hierarchical Phase), through a series of classifier combination on the last stage of the identified eight major categories on the basis of further classification [1]. Vegetation Monitoring in 2001, the world organization (Global Vegetation Monitoring unit) and the European commission's Joint Research centre (be Research Center) to perform the GLC - 2000 program (Global Land Cover 2000), in cooperation with more than 30 Research institutions worldwide, by November 1, 1999 to December 31, 2000, SPOT4 - Vegetation $1 \mathrm{~km}$ to Global Land Cover classification mapping resolution data, receive data set GLC - 2000, the data set on the classification adopted LCCS classification system. Han etc. [19] and the Chinese academy of sciences Wu Bing party by remote sensing, etc. [37] attended the GLC - 2000 program, respectively made 18 classes of French land cover classification chart and figure 22 classes of Chinese land cover classification.

(4) the domestic several classification systems. Chinese academy of sciences in 1992 to carry out the "national resources and environment remote sensing investigation and 
research in motion", established the land resources classification system, completed the TM as the main source of China's land cover/land use map [38]. In 2000, yao-zhong pan [39] based on AVHRR NDVI and climate, such as comprehensive index may evapotranspiration Holdridge PE, on China's land cover seven primary types, 47 secondary types of classification. 2002 extended exposure [40] proposed a quantitative land cover classification system. The system is based on AVHRR data, using albedo and vegetation index, land surface temperature and the net primary productivity of four indicators, according to yuan scale like the biophysical parameter values, divide the land cover types. The advantage of this classification system is classified result corresponds to the physical indicators of quantitative, make different research results can be compared each other. Liu Yonghong in 2006, such as [11] with IGBP classification system to redesign of 1:40 00000 Chinese vegetation system, puts forward the Chinese land cover classification system based on MODIS data, including seven primary categories, 22 secondary category. The classification system covers the main land cover types of IGBP, change of IGBP savanna (Savannas) into four grasslands: meadow steppe, typical steppe, desert grassland, alpine grassland; For wetland category division, including marshes and coastal wetland; At the same time, increase the farmland two partitions. The classification system has the advantage of more detailed classification, can be well response to China's actual situation.

\section{LAND COVER Classification Results OF CONTRAST}

For high resolution remote sensing image classification accuracy test results, the most direct way is to analyze precision of using GPS field sampling point. Cai-rong yue [41] in using TM data to the jinsha river valley zhaotong, mark the two urban land cover information extraction using 50 GPS data sample point after the results of comparison. Also some scholars use GPS data for $1 \mathrm{~km}$ resolution AVHRR and MODIS data comparison on the results of classification. Yao-zhong pan etc. [39] using AVHRR data in China as a reference for regional land cover mapping, northeast China and xinjiang region in hainan; the results of GPS data of Chen, etc. [42] land cover classification in northeast China are studied by using MODIS data introduced the evaluation of the accuracy of GPS field NongQing handheld GPS field fixed-point sampling data and survey data. For large area, however, for the same period of remote sensing image and GPS data is difficult; The results of the sampling points at the same time, GPS can represent 1 square kilometers area land cover situation is still uncertain.

At present, many studies using high resolution remote sensing image authentication low-resolution image classification results this practice. Classification results such as Cihlar [6] using TM AVHRR classification results of inspection: classification of the TM image into the same projection and AVHRR, with minimum distance method and TM pixels re-sampling into the same space with AVHRR classification results. MODIS soil use and land cover change research group adopts STEP (System for Terrestrial
Ecosystem Parameterization) System for the training sample collection, test and the comparison between results of classification algorithm. STEP is the collection of vegetation and environment, and other biological physical parameter database in the integration of multivariate site, by the high resolution of TM and SPOT data produced by [7]. This method sometimes for reference data image error and error factors bring to the precision of image registration.

Some research will atlas of 1:40 00000 Chinese vegetation, the "00000 China atlas of vegetation, forest distribution map, land use map and historical data, such as the land use investigation report to the comparison of the results of land cover. It is due to the historical data of production time, according to different classification standards, and the accuracy of the data of history itself, and so on factors to bring precision validation error.

\section{CONCLUSION}

Foreign land cover classification research began in the 1970 s, started late in our country, there is still a lot of meticulous work need further:

(1) Based on the research on land use and land cover classification of remote sensing technology, its key technology is the method of image classification processing information. At present, the remote sensing image classification technology is far behind the development of remote sensing technology itself. Therefore, how to effectively use the huge information source and gain high precision land cover types and the change of information, has been trying to direction.

(2) To establish a set of can reflect China's reality, and compatible with the international popular classification system, flexible conversion of land cover classification scheme, and our research results into the international land cover land use change research.

(3) To establish an open, up-to-date China land cover sample database, land cover change detection, the carbon cycle for further evaluation and climate assessment for data security.

\section{REFERENCES}

[1] ANTONIO D G, JANSEN L J M. Land cover classification system(LCCS): classification concepts and use manual[M]. Rome: FAO, 2000.

[2] DEFRIES R S, HANSEN M C, TOWNSHEND J R G, et al. Global land cover classifications at $8 \mathrm{~km}$ spatial resolution: the use of training data derived from landsat imagert in decision tree classifiers[J]. International Journal of Remote Sensing, 1998, 19(16): 3141-3168.

[3] TURNER I B L, SKOLE D, SANDERSON S, et al. Land-use and Land-cover change science/research plan, IGBP Report No.35 and HDP Report No.7[R]. Stochkholm: IGBP, 1995.

[4] TUCKER C J, TOWNSHEND J R G, GOFF T E. African land-cover classification using satellite data[J]. Science, 1985, Vol.227 No.4685: 369-375.

[5] TOWNSHEND J R G, JUSTICE C O, KALB V T. Characterization and classification of South American land cover types using satellite data[J]. International Journal of Remote Sensing, 1987, 8(8): 11891207. 
[6] CIHLAR J, HUNG L Y, XIAO Q H. Land cover classification with AVHRR multichannel composites in northern environments[J]. Remote Sensing of Environment, 1996, 58(1): 36-51.

[7] STRAHLER A, MUCHONEY D, BORAK J, et al. MODIS land cover product algorithm theoretical basis document(ATBD) version 5.0[R]. Boston: Boston University, 1999.

[8] HUETE A R, LIU H Q, BATCHILY K, et al. A comparison of vegetation indices over global set of TM images for EOS-MODIS[J]. Remote Sensing of Environment, 1997, 59(3): 440-451.

[9] Wang Z.X, et.al. MODIS enhanced vegetation index (EVI and NDVI preliminary comparison [J]. Journal of wuhan university (information science edition), 2006, 31(5): 407-410.

[10] WANG Zheng-xing, LIU Chuang, CHEN Wen-bo, et al. Preliminary comparison of MODIS-NDVI and MODIS-EVI in Eastern Asia[J]. Geomatics and information science of Wuhan university, 2006, 31(5): 407-410. (in Chinese).

[11] Liu Y.X, Niu Z, et al. Multiple classifiers in the performance evaluation of the land cover classification of remote sensing in north China [J]. Graduate school of Chinese academy of sciences journal,2005,22(6): 724-732.

[12] LIU Yong-hong, NIU Zheng, XU Yong-ming, et al. Evaluation of various classifiers on regional land cover classification in Huabei area[J]. Journal of the graduate school of the Chinese academy of sciences, 2005, 22(6): 724-732. (in Chinese).

[13] Liu Y.X, Niu Z, et al. China land cover classification system based on MODIS data design and application research [J]. Journal of agricultural engineering, 2006, 22(5): 99-104.

[14] LIU Yong-hong, NIU Zheng, XU Yong-ming, et al. Design of land cover classification system for China and its application based on MODIS data[J]. Transactions of the CSAE, 2006, 22(5): 99-104. (in Chinese).

[15] Gong Pan, Chen Z.X, Tang H.J. Based on the MODIS temperature/vegetation index of land cover classification in northeast China [J]. Journal of agricultural engineering,2006,22(9): 94-99.

[16] GONG Pan,CHEN Zhong-xin,TANG Hua-jun, et al. Land cover classification based on MODIS temperature-vegetation index timeseries data in Northeast China[J]. Transactions of the CSAE, 2006, 22(9): 94-99. (in Chinese).

[17] Liu Aixia, Liu Z.J, Wang Jing. Based on PCA transform and neural network classification method of forest graphics research in China [J]. Resources and environment in Yangtze river basin,2006,15(1): 19-24.

[18] LIU Ai-xia, LIU Zheng-jun, WANG Jing. Mapping of natural forest in China based on principal component transform and neural network classification[J]. Resources and environment in the Yangtze basin, 2006, 15(1): 19-24. (in Chinese).

[19] Nie Juan. Large scale Chinese comprehensive land cover classification comparison research [D]. Master thesis. Beijing: Beijing normal university,2003.

[20] BORAK J S, STRAHLER A H. Feature selection and land cover classification of a MODIS-like data set for a semiarid environment[J]. International Journal of Remote Sensing, 1999, 20(5): 919-938.

[21] FRIEDL M A, BRODLEY C E, STRAHLER A H. Maximizing land cover classification accuracies produced by decision trees at continental to global scales[J]. IEEE Transactions on Geoscience and Remote Sensing, 1999, 37(2): 969-977.

[22] HANSEN M C, DUBAYAH R, DEFRIES R. Classification trees: An alternative to traditional land cover classifiers[J]. International Journal of Remote Sensing, 1996, 17(5): 1075-1081.

[23] SWAIN P H, HAUSKA H. The decision tree classifier: Design and potential[J]. IEEE Transactions on Geoscience and Remote Sensing, 1977, GE-15: 142-147.

[24] HAN K S, CHAMPEAUX J L, ROUJEAN J L. A land cover classification product over France at $1 \mathrm{~km}$ resolution using SPOT/Vegetation data[J]. Remote Sensing of Environment, 2004, 92(1): 52-66.
[25] YU Feng, LI Xiao-bing, WANG Hong, et al. Land cover classification in China based on the NDVI-Ts feature space[J]. Acta phytoecologica sinica, 2005, 29(6): 934-944. (in Chinese).

[26] CARPENTER G A, GJAJA M N, GOPAL S et al. ART neural networks for remote sensing: Vegetation classification from Landsat TM and terrain data[J]. IEEE Transactions on Geoscience and Remote Sensing, 1997, 35(2): 308-325.

[27] CARPENTER G A, GROSSBERG S, MARKUZON N, et al. Fuzzy ART: A neural network architecture for incremental supervised learning of analog multidimensional maps[J]. IEEE Transactions on Neural Networks, 1992, 3(5): 698-713.

[28] GOPAL S, SKLAREW D M, LAMBIN E. Fuzzy-neural networks in multitemporal classification of land cover change in the Sahel[C] New Tools for Spatial Analysis, Luxembourg: Office for official Publications of the European Communities, 1993, 69-81.

[29] FISCHER M M, GOPAL S, STAUFER P, et al. Evaluation of neural pattern classifiers for a remote sensing application[J]. Geographical Systems, 1997, 4(1): 84-92.

[30] VAPNIK V N. Nature of statistical learning theory[M]. New York: John Wiley, 1995.

[31] CHRISTOPHER J C B. A tutorial on support vector machines for pattern recognition[J]. Data Mining and Knowledge Discovery, 1998, 12(2): 121-167.

[32] HUANG C, DAVIS L S, TOWNSHEND J R G. An assessment of support vector machines for land cover classification[J]. International Journal of Remote Sensing, 2002, 23(4): 725-749.

[33] FU Wen-jie, HONG Jin-yi, LIN Ming-sen. A method of land use classification from remote sensing image based on support vertor machines and spectral similarity scale[J]. Remote sensing technology and application, 2006, 21(1): 25-30. (in Chinese).

[34] PAUL M. Application of satellite and GIS technologies for landcover and land-use mapping at the rural-urban fringe: A case study[J] PE \& RS, 1992, 58(4): 439-448.

[35] GUO Peng, SUN Yan-ling, LIU Hong-bin, et al. A study of knowledge-based remote sensing classification for LUCC(Land Use/Cover Classification)[J]. Journal of southwest agricultural university, 2003, 25(3): 279-282. (in Chinese).

[36] DI Kai-cang, LI De-ren, LI De-yi. Study of remote sensing image classification based on spatial data mining technique[J]. Journal of Wuhan Technical University of Surveying and Mapping, 1997, 12(4): 42-48.

[37] USGS. National Land Cover Characterization[EB/OL]. http://landcover.usgs.gov/ natllandcover.asp. (2003-10-20) [2005-08$12]$

[38] LOVELAND T R, REED B C, BROWN J F, et al. Development of a global land cover characteristics database and IGBP DISCover from $1 \mathrm{~km}$ AVHRR data[J]. International Journal of Remote Sensing, 2000, 21(6\&7): 1303-1330.

[39] HANSEN M C, DEFRIES R S, TOWNSHEND J R G, et al. Global land cover classification at $1 \mathrm{~km}$ resolution using a decision tree classifier[J]. International Journal of Remote Sensing, 2000, 21(6\&7): 1331-1364.

[40] BING FANG W. The land cover map for China in the year 2000, GLC2000 database[R]. Europe: Commision Joint Research Centre, 2003. http://www-gvm.jrc.it/GLC2000.

[41] PAN Yao-zhong, LI Xiao-bing, HE Chun-yang. Research of comprehensive land cover classification in China: based on MOAA/AVHRR and holdridge PE index[J]. Quaternary sciences, 2000, 20(3): 270-281. (in Chinese).

[42] YUE Cai-rong. A study on technique of land/use land-cover investigation by remote sensing in Jinshajiang river basin[J]. Journal of Southeast forestry college, 2003, 23(2): 44-48. (in Chinese).

CHEN Jian-jun, ZHANG Shu-wen. Accuracy assessment of Northeast China's land cover classification using MODIS data[J]. Advances in marine science, 2004, 22, Supplement, 51-57. (in Chinese) 